How Institutions Shape Trust during Collective Action: A Case Study of Forest Governance on Haida Gwaii

\author{
Ngaio Hotte \\ (Faculty of Forestry, University of British Columbia) \\ Robert Kozak \\ (Faculty of Forestry, University of British Columbia) \\ Stephen Wyatt \\ (University of Moncton)
}

Prepared for delivery at the Workshop on the Ostrom Workshop (WOW6) conference, Indiana University Bloomington, June 19-22, 2019. (C Copyright 2019 by author(s) 


\title{
How institutions shape trust during collective action: A case study of forest governance on Haida Gwaii ${ }^{\text {it }}$
}

\author{
Ngaio Hotte ${ }^{\mathrm{a}, *}$, Robert Kozak ${ }^{\mathrm{a}}$, Stephen Wyatt ${ }^{\mathrm{b}}$ \\ ${ }^{a}$ Faculty of Forestry, University of British Columbia. 2424 Main Mall, Vancouver, BC V6T 1Z4, Canada \\ ${ }^{\mathrm{b}}$ Université de Moncton, Campus d'Edmundston, Pavillon de foresterie, 165, boulevard Hébert, Edmundston, NB E3V 2S8, Canada
}

\section{A R T I C L E I N F O}

\section{Keywords:}

Collective action

Institutions

Trust

Indigenous

Co-management

Governance

\begin{abstract}
A B S T R A C T
Trust between actors involved in collective action can lower transaction costs, create incentives to invest in collective activities and help actors to achieve joint gains. While existing theoretical frameworks note the importance of institutions for motivating trust and the trust literature identifies characteristics of institutions that motivate trust, empirical research regarding natural resource governance is needed to inform development of institutions for this type of collective action situation. This paper builds on an existing theoretical framework linking institutions, trust and collective action by exploring the characteristics of institutions that motivate trust. Empirical grounding was provided in the form of a case study of collaborative forest governance on Haida Gwaii, an archipelago located off the coast of British Columbia, Canada. Conflict between the Council of the Haida Nation and the Province of British Columbia regarding widespread industrial logging led the two parties to establish two structures to collaboratively govern forests and lands on Haida Gwaii: the Haida Gwaii Management Council and the Solutions Table. Interviews with past and present members of the Haida Gwaii Management Council and the Solutions Table were used to identify three forms of formal rules and one form of informal rules as well as fourteen associated characteristics that motivated trust. Cluster analysis reduced the fourteen characteristics to four clusters: alignment of interests, fairness, cohesion and satisfactory terms of cooperation.
\end{abstract}

\section{Introduction}

Trust is known to be important for collective action (Kahan, 2003). Individuals who have faith that others will contribute to collective activities will voluntarily respond in kind, leading to subsequent cooperation in kind as individuals observe others contributing to public goods (Kahan, 2003; Berkes, 2010). Mutual trust also lowers transaction costs associated with monitoring others' actions (Kramer and Tyler, 1996; Pretty and Ward, 2001; Vanni, 2014) and administering incentive schemes to entice compliance (Kahan, 2003). In her Nobel Prize ${ }^{1}$ lecture, Dr. Elinor Ostrom noted the "central role of trust" in addressing collective action problems among individuals involved in multi-level, polycentric governance of common-pool resources (Ostrom, 2009). Her lecture concluded with a call to identify how institutions help or hinder collective action, including by motivating trust (Ostrom, 2009).
However, trust remains an understudied construct within the context of collective action. While some scholars have explored the role of social capital and norms (e.g. Keefer and Knack, 2005; Ostrom and Ahn, 2009), literature on collective action "has paid more attention to payoff functions than to how individuals build trust" (Ostrom, 2009). The trust literature offers insights regarding characteristics of institutions that motivate trust and Farrell (2009a,b) calls for "a properly developed theoretical account of how trust and institutions interact." Ostrom and Ahn (2009) provide a theoretical foundation for this work by outlining the relationship between institutions, trust and collective action. Empirical research, including case studies, can help to identify which characteristics of institutions that appear in the trust literature are particularly relevant for motivating trust and, subsequently, collective action.

Collaborative forest governance on Haida Gwaii, an archipelago

\footnotetext{
* This article is part of a special issue entitled "Governing our forests: The evolving political economy of multiple values and multiple stakeholders," published at the journal Forest Policy and Economics 107C, 2019.

* Corresponding author.

E-mail address: ngaio.hotte@alumni.ubc.ca (N. Hotte).

${ }^{1}$ Ostrom received the Sveriges Riksbank Prize in Economic Sciences in Memory of Alfred Nobel; commonly (inaccurately) referred to as the Nobel Prize in Economics.
} 
located off the coast of British Columbia, Canada, offers an opportunity to explore the characteristics of institutions that motivate trust to support collective action. Conflict between the Council of the Haida Nation and the Province of British Columbia (B.C.) regarding widespread industrial logging led the two parties to sign a Reconciliation Protocol in 2009, which established two distinct but related structures to govern forest and land use on Haida Gwaii: the Haida Gwaii Management Council (HGMC) and the Solutions Table. This paper presents a case study of the characteristics of institutions that motivate trust based on interviews with past and present members of the Haida Gwaii Management Council and of the Solutions Table.

As Indigenous communities across Canada - and around the world regain control over lands and resources, experiences from Haida Gwaii can provide insights for how institutions can motivate trust and support collective action involving Indigenous and non-Indigenous governments. This paper builds on an existing theoretical framework that links institutions, trust and collective action (Ostrom and Ahn, 2009) and characterizes institutions that motivate trust to support collective action based on empirical research from a case study of collaborative forest governance on Haida Gwaii.

\subsection{Trust, collective action and the role of institutions}

Ostrom and Ahn (2009) outline the relationship between institutions, trust and collective action (Fig. 1). According to this framework, forms of social capital - including trustworthiness, networks and institutions - motivate trust which, subject to contextual variables, supports collective action.

Trust has been explored from the disparate perspectives of economics, management, marketing, psychology and sociology and is defined in many ways throughout these bodies of literature (Castaldo, 2002; Castelfranchi and Falcone, 2010; Schilke et al., 2015). One common definition, employed in Ostrom and Walker (2003: 6), describes trust as the "intention to accept vulnerability based upon positive expectations of the intentions of the behavior of another" (Rousseau et al., 1998: 395). The perception of trust by an individual, referred to as "subjective trust," is believed to arise as result of the existence of trust antecedents which motivate trusting actions, or "behavioural trust" (Gillespie, 2003; Das and Teng, 2004; Colquitt et al., 2007; Gillespie, 2012). Antecedents of trust include actions such as making promises, shaping expectations of behavior, expressing normative values and developing a shared identity (Davis and Holt, 1993; Ostrom, 2003). Trust between actors involved in collective action can enable joint gains that exceed the value of those possible through acting alone (Ostrom and Walker, 2003). Mutual trust also lowers transaction costs by reducing the need to monitor others (Pretty and Ward, 2001; Vanni, 2014) and creating incentives to invest in collective activities based on confidence that others will do the same (Berkes, 2010). However, the temptation to betray another's trust - for example, by breaching the terms of a contract or agreement - in pursuit of shortterm gain creates a challenging environment for building or maintaining trust among actors (Ostrom, 2003). Despite this temptation, people cooperate more frequently than rational choice models would predict (Davis and Holt, 1993: 325; Ostrom, 2003). "Building trust," notes Ostrom $(2003,34)$ "appears to be a key link in the communication-cooperation connection."

Poteete et al. (2009) note that early theories of collective action focused on individual resource users acting independently and in selfinterest, leading to resource depletion if not for private ownership or regulation (Poteete et al., 2009). Examples included the Tragedy of the Commons (Hardin, 1968), the Prisoner's Dilemma (Rapoport and Chammah, 1965) and the problem of free-riding (Olson, 1965). However, field-based studies documented many cases of successful collective natural resource governance in the absence of private ownership or government regulation, leading game theorists and other scholars to develop new equilibrium concepts and more realistic models of human

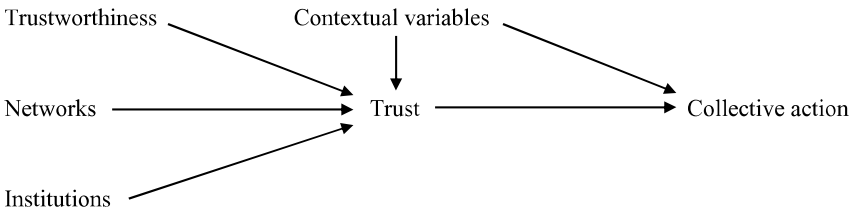

Fig. 1. Trust, forms of social capital and their linkage to achieving collective action (Ostrom and Ahn, 2009).

behavior and strategic interaction (Poteete et al., 2009). This included development of the Institutional Analysis and Development Framework (Kiser and Ostrom, 1982) which sought to explain collective action in field settings of diverse and complex institutions (Poteete et al., 2009). Thus, early explorations of collective action that focused on actions taken by a group of individuals in pursuit of members' perceived shared interests (Marshall, 1998) gave way to analyses of complex, multilevel and polycentric institutions (Poteete et al., 2009), including co-management (Berkes, 2009; Vanni, 2014) and institutional collective action (Feiock, 2013).

Co-management describes a partnership that bridges levels of governance by sharing power, knowledge and responsibility between a central government and local resource users (Singleton, 1998: 7; Berkes, 2009: 1692; Berkes, 2010; Vanni, 2014). In such arrangements, different levels of organizations bring their respective comparative advantages in generating and mobilizing knowledge at different scales (Vanni, 2014: 28) to support collective action through increased efficiency and legitimacy (Singleton, 1998: 3). By comparison, institutional collective action (ICA) describes decisions that involve two or more independent formal authorities (Feiock and Scholz, 2010; Feiock, 2013). ICA recognizes that, while only individuals are capable of action, individuals often act as composite actors in the name of or in the interest of a group or organization (Ostrom, 2005; Feiock and Scholz, 2010: 7). Such arrangements can result in collective action dilemmas among government authorities "similar to those much-studied problems for individuals" (Feiock and Scholz, 2010: xv) in which decisions made by one independent formal authority do not consider costs or benefits imposed on others (Feiock and Scholz, 2010; Feiock, 2013). However, in both types of arrangements, collective action may be motivated by the potential to increase quality and lower cost of information, enhance effectiveness of monitoring and enforcement and increase legitimacy of the system through involvement of multiple actors in its development (Vanni, 2014).

Institutions are an important form of social capital that can help actors increase trust during collective action (Ostrom and Ahn, 2009). They can act as antecedents of trust by creating favourable assumptions and expectations about a potential trustee's behaviour and reducing the risk of one or more parties behaving in an untrustworthy manner (Möllering, 2006; Farrell, 2009a, 2009b; Bachmann and Inkpen, 2011). The trust literature refers to this phenomenon as "institution-based trust" (Bachmann and Inkpen, 2011) and describes how institutions can offer assurances (e.g. Yamagishi and Yamagishi, 1994) to prospective trustors and sanctions (e.g. Shapiro et al., 1992) to potential defectors. Ostrom (1986, 1990: 51, 2011) defines institutions as "the sets of working rules that are used to determine who is eligible to make decisions in some arena, what actions are allowed or constrained, what aggregation rules will he used, what procedures must be followed, what information must or must not be provided and what payoffs will be assigned to individuals dependent on their actions." This set of rules typically includes some combination of formal rules, such laws, agreements and contracts, as well as informal rules, such as customs, traditions and norms (Coleman, 1990; Coletti et al., 2005; Bachmann and Inkpen, 2011), that collectively represent shared understandings among actors regarding what actions are required, prohibited or permitted (North, 1990; North, 1991; Crawford and Ostrom, 2005; Ostrom, 2011). Such institutions are used by individuals to organize 
Table 1

Characteristics of institutions that motivate trust (Hotte et al., 2019).

\begin{tabular}{|c|c|}
\hline Influence on trust & Source \\
\hline Justice, fairness and expectations & $\begin{array}{l}\text { Aryee et al. (2002); Dirks and Ferrin } \\
(2002)\end{array}$ \\
\hline Alignment of interests; value alteration; selectivity in transactions; research/information revelation & Bhattacharya et al. (1998) \\
\hline Norms; sanctions & Coleman (1990) \\
\hline Control systems & Coletti et al. (2005) \\
\hline $\begin{array}{l}\text { Mutual interests; interpersonal trust; joint dispute resolution; policies and procedures; reporting structure; staffing and training; } \\
\text { decision-making process; rituals, ceremonies and networking; proactive information collection; setting objectives; planning and } \\
\text { budgeting }\end{array}$ & Das and Teng (2001) \\
\hline Interaction frequency; symmetry of dependence; multiplexity of relationships and cooperation-related incentives & Eberl (2003) \\
\hline Structural assurance belief; situational normality belief & McKnight et al. (1998) \\
\hline Expectations embedded in norms, structures and institutions & Newell and Swan (2000) \\
\hline Interaction of past exchange experiences and expectations of continuity & Poppo et al. (2008) \\
\hline Power in social exchange & $\begin{array}{l}\text { Schilke et al. (2015); Wu and Wilkes } \\
\text { (2016) }\end{array}$ \\
\hline Leadership styles & Schaubroeck et al. (2011) \\
\hline Affect; emotion; violation and repair; distrust; international and cross-cultural issues & Schoorman et al. (2007) \\
\hline Communication; cooperation; performance & Seppanen et al. (2007) \\
\hline Relational form, depth and risks & Sheppard and Sherman (1998) \\
\hline Type of instigation; network size; flexibility/adaptability; influence & Willem and Lucidarme (2014) \\
\hline System-based trust (satisfactory terms, adoption of alternative dispute resolution, reputation) & Wong and Cheung (2005) \\
\hline
\end{tabular}

and govern themselves to reduce information asymmetry, provide guidelines for behaviour and increase the likelihood of collective action by reducing the temptation to defect - in essence, to behave in a trustworthy manner (Möllering, 2006; Bachmann and Inkpen, 2011). Because rules are subject to interpretation (Aligica and Boettke, 2009, 2011), stability of actions based on rules hinges on existence of shared meaning among actors (Ostrom, 2011). However, shared meaning itself can shift over time due to changes in norms, events or the state of knowledge (Ostrom, 1980).

The trust literature points to several characteristics of institutions that motivate trust by creating favourable or unfavourable assumptions and expectations about actors' behaviour (Bachmann and Inkpen, 2011). These characteristics are summarized in Table 1 . However, this literature encompasses a broad range of institutions. While it offers a list of characteristics of institutions that may be conducive to trust, empirical research regarding natural resource governance institutions is needed to inform development of formal and informal rules that are tailored to this type of collective action situation (Ostrom, 2009).

Contextual issues of power also have important implications for trust and collective action in co-management and ICA arrangements. Because institution-building occurs in a particular political, social and economic context (Prabhu et al., 2007; Berkes, 2010), the ability to exercise power and the kinds of powers held be each party can shape institutions in important ways (Ribot et al., 2006; Berkes, 2010). For example, rules may be crafted by actors themselves, imposed by one governing body or some combination thereof and are shaped by exogenous influences. While Ostrom (1990) asserts that resource users themselves must devise their own rules, norms, and sanctions to ensure that group interests are in line with those of individuals to influence behaviour and create legitimacy (Vanni, 2014), the level of powersharing, devolution of powers and retention of existing powers may be more strongly influenced by one party in co-management - typically, by state governments. And while formal rules are explicitly negotiated, informal rules often emerge from independent instances of social bargaining between actors in a manner that reflects implicit power relations (Farrell, 2009a,b). Actors that are more powerful may be expected to be more successful in these social bargaining situations, with actors' expectations crystallizing over time and reinforcing imbalances of power (Farrell, 2009a,b). If one party possesses a high degree of power, they may have little or no incentive not to renege on their commitments (Farrell, 2009a,b). Thus, the risk of trusting may be perceived by a potential trustor as too great. Trust is only possible to the extent that both parties value continuation of the relationship and have some reason to take the other's interest into account (Farrell, 2009a,b).

\subsection{Collaborative forest governance and trust on Haida Gwaii}

Collaborative management, or collaborative governance, are often used as synonyms for co-management (Berkes, 2010). In Canada, collaborative management typically refers to an informal (non-legal) relationship, while the term co-management is reserved for formal powersharing arrangements involving a state government and local resource users (Berkes, 2009, 2010). However, no single, universally accepted definition of co-management exists because there is a continuum of arrangements with different degrees of power sharing (Pinkerton, 1989; Armitage et al., 2007; Berkes, 2010). Where two or more parties to a comanagement agreement participate and share power under their own authorities, the relationship resembles an ICA arrangement. At the other end of this continuum, participation in collaborative governance may be limited to an advisory capacity (Bowie, 2013).

Approximately 490 bilateral and trilateral agreements have established collaborative governance arrangements involving Indigenous organizations and governments and provinces regarding lands, resources and economic development in Canada (Papillon, 2015). Development of these agreements has been motivated by a combination of jurisprudence regarding Aboriginal rights and title (e.g. Delgamuukw $v$. British Columbia, Haida Nation v. British Columbia) and conflict associated with increasing pressure on natural resources (Papillon, 2015). These institutions have developed in an environment where trust is particularly elusive due to a history of assimilation and domination carried out under Canadian laws such as the Indian Act (Blackstock, 2001). These laws have, over the past 150 years, been used to restrict First Nations ${ }^{2}$ Peoples' freedom to practice their culture, to access the justice system and to self-determination, among other injustices (Blackstock, 2001; Carlson, 2010; Coates and Carlson, 2013). Federal and provincial institutions treated First Nations people as inferior and assumed responsibility for decisions on their behalf, including through the reserve and residential school systems (Blackstock, 2001). While some blatantly discriminatory elements of the Indian Act have been removed, the colonial intent of the Act is preserved in its remaining form. This legacy has generated conflict and mistrust between First Nations and federal or provincial governments (Canada et al., 1996;

\footnotetext{
${ }^{2}$ In Canada, Indigenous Peoples are variously described as belonging to one of three groups: First Nations, Inuit or Métis. The Haida are one of the First Nations (Takeda and Røpke, 2010).
} 
Table 2

Documents that outline formal rules for collective action for forest governance on Haida Gwaii.

\begin{tabular}{|c|c|}
\hline Agreement & Highlights \\
\hline Strategic Land Use Agreement (2007) & $\begin{array}{l}\text { - Outlined sustainable forestry practices } \\
\text { - Established terrestrial protected areas over } 52 \% \text { of land area } \\
\text { - Described interim and permanent protection measures for new protected areas } \\
\text { - Identified land use objectives and governance structures } \\
\text { - Lowered the annual allowable cut (AAC) from } 2.2 \text { million cubic metres per year }\left(\mathrm{m}^{3} / \mathrm{y}\right) \text { to } 800,000 \mathrm{~m}^{3} / \mathrm{y} \\
\text { - Committed to joint analysis and determination of future timber harvest }\end{array}$ \\
\hline Kunst'aa guu-Kunst'aayah Reconciliation Protocol (2009) & $\begin{array}{l}\text { - Committed to seeking "a more productive relationship" } \\
\text { - Represented "an incremental step in a process of reconciliation of Haida and Crown titles" } \\
\text { - Outlined shared and joint decision-making respecting lands and resources on Haida Gwaii } \\
\text { - Introduced the Haida Gwaii Management Council and Solutions Table }\end{array}$ \\
\hline Land Use Objectives Order (2010) & $\begin{array}{l}\text { - Addressed technical components of ecosystem-based management } \\
\text { - Expanded on Province-wide land use objectives to include locally-important cultural and ecological features }\end{array}$ \\
\hline Haida Gwaii Reconciliation Act (2010) & $\begin{array}{l}\text { - Delegated authority for the following decisions to the Haida Gwaii Management Council: } \\
\text { o Determining the Annual Allowable Cut for timber } \\
\text { o Establishing and amending objectives for the use and management of land and resources } \\
\text { o Developing protected area management plans } \\
\text { o Establishing policies and standards for identification and conservation of heritage sites }\end{array}$ \\
\hline
\end{tabular}

Blackstock, 2001) and has important implications for how power is shared in collaborative governance by assigning authority for natural resource decisions primarily to federal and provincial governments.

Collaborative forest governance on Haida Gwaii, which involves the Council of the Haida Nation and the Province of B.C., has developed against the backdrop of this legacy and the history of industrial resource extraction it supported (Lee, 2012). Haida Gwaii, known for a time as the Queen Charlotte Islands, is an archipelago of more than 350 islands located off the North Coast of British Columbia, Canada, and home to some of the world's last remaining tracts of intact coastal temperate rainforest (Gaston et al., 2008; Takeda and Røpke, 2010). The cool, oceanic, humid-perhumid climate, with mean annual precipitation of 1100 to $4200 \mathrm{~mm}$ (Environment Canada, 1980), supports a range of ecosystems, a largely forested landscape (Gaston et al., 2008) and a current annual allowable cut of 921,500 cubic metres per year through licenses administered by the Province of B.C. (BC MFLNRO, 2012).

The Haida's connection to the lands and waters of Haida Gwaii dates back more than 10,000 years (Takeda and Røpke, 2010). Throughout the 20th century, Haida Gwaii was subject to widespread industrial logging and the Haida were denied a voice in natural resource governance decisions by federal and provincial governments (Takeda and Røpke, 2010). Even after a Supreme Court ruling in Haida Nation $v$. British Columbia recognized the strength of the Haida's claim to Aboriginal title and established the Province of B.C.'s obligations regarding consultation and accommodation (Jones et al., 2017), the Province of B.C. failed to act accordingly in its decision regarding a forest tenure (Takeda and Røpke, 2010).

This failure sparked a protest in 2005, called Islands Spirit Rising, which focused on increasing the role of the Haida in forest governance (Dean, 2009). The protest generated political pressure that resulted in interim protection for culturally and ecologically significant areas and features, launched a renewed land use planning process and set in motion a series of negotiations that led to four documents that underpin collective action for forest governance on Haida Gwaii (Table 2) (Council of the Haida Nation and Province of British Columbia, 2007, 2017; Council of the Haida Nation, November 2010; Takeda and Røpke, 2010; Egan, 2011).

These four documents, the terms of which were negotiated and agreed to by the Council of the Haida Nation and the Province of B.C., provided the basis for formal rules for two governing bodies: the Haida Gwaii Management Council and the Solutions Table (Fig. 2). The former consists of two representatives of the Council of the Haida Nation, two representatives of the Province of B.C. and one neutral chairperson who is jointly appointed. The latter also includes four members, two from the Council of the Haida Nation and two from the Province of B.C.; however, one co-chair is appointed from each organization. While the Haida Gwaii Management Council makes decisions, the Solutions Table is a vehicle for consultation and accommodation.

These developments have increased the degree of influence of the Council of the Haida Nation over decisions about lands and resources on Haida Gwaii relative to the former top-down governance approach. Collective action on forest governance has led the Haida to achieve several of their goals for resource management including protection of Haida cultural sites, a 50\% reduction in the annual allowable cut of forests, implementation of ecosystem-based management and a doubling of the area of parks and protected areas (Penikett, 2012). Consequently, this approach to forest governance is often looked to as an example by other jurisdictions (e.g. National Centre for First Nations Governance, 2013; Dowie, 2017: vii).

The events leading up to the establishment of collaborative forest governance on Haida Gwaii illustrate a fundamental ICA dilemma: as resource use began to approach a critical threshold, decisions by one government with formal authorities over aspects of forest and lands management (i.e. the Province of B.C.) imposed growing negative externalities on another government and rights holder (i.e. the Council of the Haida Nation) (Feiock and Scholz, 2010). The existence of these negative externalities led to conflict and transaction costs in the form of litigation and protest. To achieve both governments' objectives, representatives of the Council of the Haida Nation and the Province of B.C. had to move from a place of distrust and conflict to one of collective action. These developments have increased the degree of influence of the Council of the Haida Nation over decisions regarding lands and resources on Haida Gwaii compared to other top-down Provincial governance approaches. Trust has been essential for these collaborations, which are indicative of a broader shift in government-to-government relationships involving Indigenous communities across Canada. The experiences of individuals involved in forest governance through the Haida Gwaii Management Council and the Solutions Table can offer insights regarding how formal and informal rules can motivate trust among actors in collective action situation. By empirically examining the institutional rules that motivate trust in forest and land management processes on Haida Gwaii, this research also addresses Ostrom's call to action to identify institutional rules that motivate trust and support collective action.

\section{Methods}

A case study approach was used to empirically examine characteristics of formal and informal rules that motivate trust among actors involved in collective action for forest governance on Haida Gwaii. This approach was chosen because it provides an opportunity to examine 


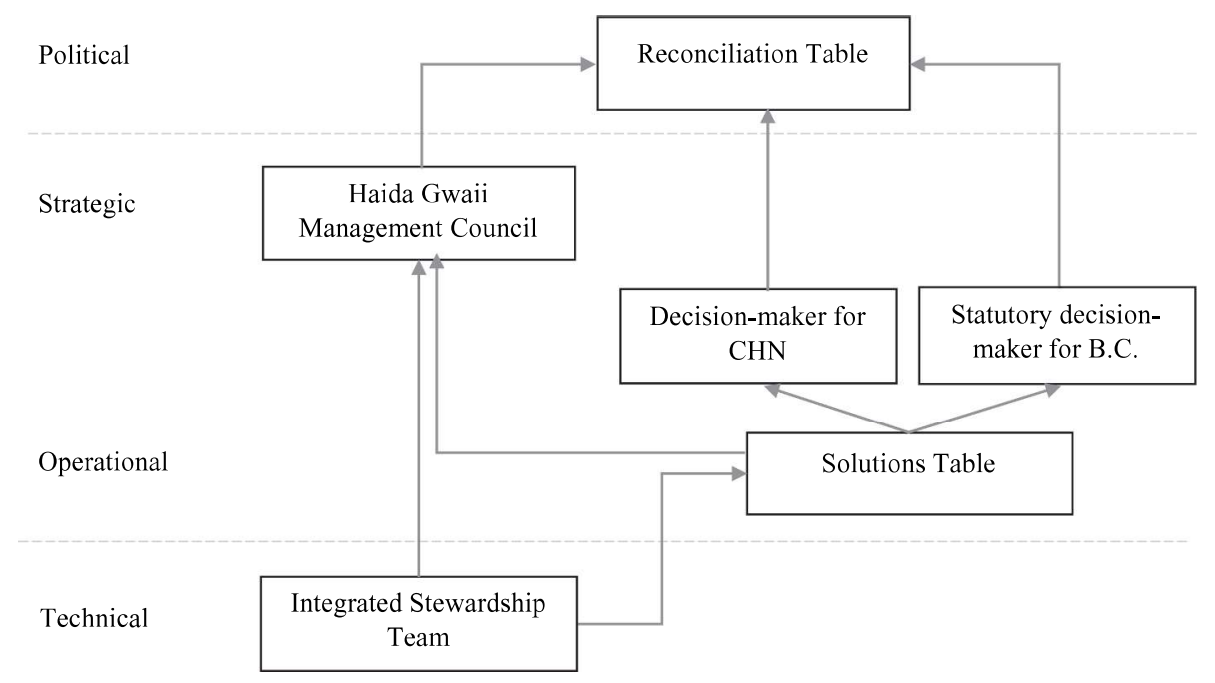

Fig. 2. Governing bodies involved in forest and land management on Haida Gwaii. (Hotte et al., 2019).

logic posited by theorists by comparing empirical evidence with relevant theories and determining whether it is consistent or challenging (Janssen and Ostrom, 2006). Case studies have been used extensively in the literature regarding collective action theory to compare logic posited by theorists to empirical evidence, determining whether it is consistent or challenging (Janssen and Ostrom, 2006).

In this study, we empirically examined characteristics of formal and informal rules that motivated trust among actors involved in collective action for forest governance on Haida Gwaii through the Haida Gwaii Management Council and the Solutions Table (the "collaborations"). The research was planned cooperatively with representatives of the Council of the Haida Nation (CHN) and the Province of B.C., with approval subsequently sought and obtained from both the CHN and the Office of Research Ethics at the University of British Columbia (UBC).

Data was obtained through semi-structured, in-depth interviews with seventeen people who are currently or were formerly involved in one of the collaborations for a period of at least one year. This included eight representatives of the Council of the Haida Nation, nine representatives of the Province of B.C. and two individuals who had participated in the Haida Gwaii Management Council as neutral chairs. All interviews were conducted by the lead author on Haida Gwaii, either in person or by telephone, over a two-month period beginning in mid-February 2017. These interviews explored experiences of individuals in the collaborations, their perceptions of trust and influences that they felt shaped these perceptions. Open-ended questions (e.g. "Tell me about your experiences with X.") and clarifying questions (e.g. "Can you give me an example of Y?") focused on subjective and behavioural trust (Gillespie, 2003; Das and Teng, 2004; Colquitt et al., 2007; Gillespie, 2012) and followed an unconstrained format and allowed conversation to flow naturally (Rubin and Rubin, 2005). Questions focused primarily on collective choice rules, which determine who is eligible to make operational rules and how they may be made and changed (Kiser and Ostrom, 1982; Ostrom, 2005), as these are most relevant to the collective action situations in which interviewees operate. Interviews were audio-recorded, transcribed verbatim and systematically coded and analyzed using NVivo software (Rubin and Rubin, 2005).

NVivo 11 software supported interpretation of qualitative codes and abstraction of themes. Initial codes regarding characteristics of institutions that motivate trust were identified from peer-reviewed literature (Table 1). This initial list of codes was expanded during interviews to capture participant experience, support analysis from both theoretical and emergent perspectives and create a typology based on related concepts (Rubin and Rubin, 2005). Codes regarding the forms of formal and informal rules used by the Haida Gwaii Management Council and the Solutions Table were identified from the interviews. A codebook was maintained in NVivo 11 that contained a list of codes accompanied by a definition, brief description, instructions for when to use the code and when not to use the code (i.e. inclusion and exclusion criteria) and an example (Rubin and Rubin, 2005). A sample of three transcripts was coded by an independent researcher, who was not affiliated with the research, to analyze internal consistency of codes based on a comparison of codes assigned by the lead author and the independent researcher. Internal consistency was analyzed using Cohen's kappa $(\kappa=0.44)$ and weighted kappa statistic $\left(\kappa_{\mathrm{W}}=0.44\right)$ (Davey et al., 2010). These coefficients indicate fair to moderate (George and Mallery, 2003) agreement between coders. Due to the large number of codes used in this study, this level of interrater reliability was deemed acceptable.

Data analysis was performed in an iterative cycle that allowed continuous comparison of new results with previous findings to inform subsequent analysis (Rubin and Rubin, 2005). Once all interviews had been coded, transcripts were reviewed again and, where necessary, recoded to reflect codes that had been derived through subsequent interviews. Agglomerative hierarchical cluster analysis was then performed using NVivo 11, which employs the complete linkage (i.e. farthest neighbour) algorithm to calculate Pearson correlation coefficients based on words within each theme and concept code. The most similar concepts were grouped under their respective themes to develop a coherent narrative of the trust-building process across cases. The resulting coding structure is represented in Appendix I.

A matrix query was conducted in NVivo to identify references to that linked rules-in-use and characteristics that motivated trust. Query results were exported to Microsoft Excel and an "if" statement was used to convert numerical data to a qualitative indicator of presence ("X") or absence (") at each intersection. Cutting and sorting was then used to identify quotes that described characteristics of rules-in-use that motivate trust (Ryan and Bernard, 2003). Expert views are reported anonymously; numbers in parentheses that follow interview quotes indicate a specific interviewee response.

\section{Results}

Interviewees described three forms of formal rules (agreements, procedures and terms of reference and legislation) and one form of informal rules (norms), as well as fourteen associated characteristics 
Table 3

Characteristics of formal and informal rules that motivate trust.

\begin{tabular}{|c|c|c|c|c|c|c|c|c|c|c|c|c|c|c|c|}
\hline & & \multicolumn{14}{|c|}{ Characteristics of rules } \\
\hline & & \multicolumn{6}{|c|}{ Alignment of interests } & \multicolumn{2}{|c|}{ Fairness } & \multicolumn{2}{|c|}{ Cohesion } & \multicolumn{4}{|c|}{ Satisfactory terms } \\
\hline & & 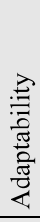 & 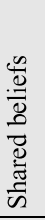 & 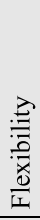 & 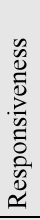 & 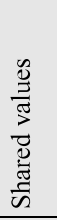 & 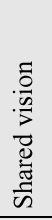 & $\begin{array}{l}\stackrel{\Xi}{\Xi} \\
\stackrel{\Xi}{\Xi} \\
\stackrel{\leftrightarrows}{\Xi} \\
\end{array}$ & 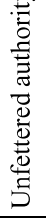 & 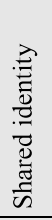 & $\begin{array}{l}\overrightarrow{3} \\
\frac{\overrightarrow{0}}{\pi} \\
\frac{\pi}{2}\end{array}$ & 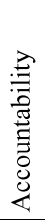 & 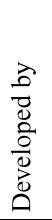 & 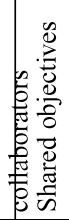 & 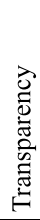 \\
\hline \multirow{4}{*}{ 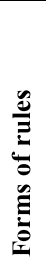 } & Agreement & $\mathrm{X}$ & $\mathrm{X}$ & $\mathrm{X}$ & $\mathrm{X}$ & $\mathrm{X}$ & $\mathrm{X}$ & $\mathrm{X}$ & $\mathrm{X}$ & $\bar{X}$ & $\mathrm{X}$ & $\mathrm{X}$ & $\mathrm{X}$ & $\mathrm{X}$ & $\mathrm{X}$ \\
\hline & $\begin{array}{l}\text { Procedures and } \\
\text { terms of reference }\end{array}$ & $\mathrm{X}$ & & & $\mathrm{X}$ & $\mathrm{X}$ & $\mathrm{X}$ & $\mathrm{X}$ & $\mathrm{X}$ & $\mathrm{X}$ & $\mathrm{X}$ & $\mathrm{X}$ & $\mathrm{X}$ & $\mathrm{X}$ & $\mathrm{X}$ \\
\hline & Legislation & $\mathrm{X}$ & & $\mathrm{X}$ & & $\mathrm{X}$ & & $\mathrm{X}$ & & & & $\mathrm{X}$ & $\mathrm{X}$ & $\mathrm{X}$ & \\
\hline & Norms & $\mathrm{X}$ & $\mathrm{X}$ & $\mathrm{X}$ & & $\mathrm{X}$ & & $\mathrm{X}$ & & $\mathrm{X}$ & $\mathrm{X}$ & & $\mathrm{X}$ & & $\mathrm{X}$ \\
\hline
\end{tabular}

that motivated trust. Cluster analysis reduced the fourteen characteristics to four clusters: alignment of interests, fairness, cohesion and satisfactory terms of cooperation. These forms of rules and the characteristics that motivate trust are summarized in Table 3 and described in this section, supplemented by excerpts from participant interviews.

\subsection{Agreements}

Agreements were noted to provide clarity regarding shared objectives and secure commitment among actors. Importantly, interviewees noted that these agreements should be developed by both parties, recognize respective authorities of the parties and commit them to jointly developing further rules such as procedures and terms of reference.

"We agree that [the forests and lands] can be looked after, and we agree to a structure to look after them and then develop the rules there." (Interviewee 9).

Several interviewees from both collaborations also noted that agreements should be adaptable to evolving needs of both governments over time. Representatives from both governments acknowledged frustrations resulting from the pace and degree of change since the Kunst'aa guu-Kunst'aayah Reconciliation Protocol was signed. This particular agreement, named with the Haida word for "the beginning" (Dowie, 2017: 125), was intended to mark the beginning of a new relationship among the parties. However, a few interviewees noted that changing political priorities have reduced political will to continue to work on the relationship. This has been viewed by some as a lack of commitment, which has led to a decline in trust.

"[...] we agree that these are the things we need to move on jointly now and everything else, we need a better system than we had before and we need to work on what the future of those decisions and that kind of engagement is going to look like as time goes along, into the future." (Interviewee 14).

"[...] trust is continuing to build on a relationship, keep moving forward in some fashion, but also keep understanding that there's two partners in the relationship that demand attention." (Interviewee 5).

Agreements can also act as a substitute for trust, especially due to the changing nature of governments. While mutual understanding may be reached among senior leaders within two governments at a particular time, changes in one or both governments can lead to shifting priorities. Agreements enshrine commitments made by both governments and provide a point of reference that reduces the risk of engaging in collective action.

"[...] don't leave them to trust, but rather, be clear about what the arrangement is $[\ldots]$ down to the signed agreement." (Interviewee 9).

Interviewees also specifically noted the importance of two elements of agreements - decision-making processes and joint dispute resolution.

Joint decision-making, which is used by members of the Haida Gwaii Management Council members and requires consensus except in the event of a tie-breaking vote, provides both parties with equal influence and was viewed as having a positive influence on trust. Joint decision-making was viewed as appropriate by representatives from both governments given the strength of claim to Aboriginal title of the Haida.

"[It's a] very positive process. It's not perfect but it's very positive and it was built together. And we have equal say there." (Interviewee 1).

"You have representatives that have equal authority, no more, no less, than the representatives that the other party has." (Interviewee 14).

In contrast, the Solutions Table uses shared decision-making, under which the Province of B.C. retains authority for making final decisions on applications. Consensus is not required among collaborators, which has created tensions between the two governments. While collaborators attempt to reach consensus on applications, the Province of B.C. can and, in some cases, must under Provincial legislation, make a unilateral decision to sign off on an application that is opposed by representatives of the Council of the Haida Nation if it meets the technical requirements established by the Land Use Objectives Order.

"At the Solutions Table proper, it's pretty equal. When it [leaves] the Solutions Table, it's unequal. The Crown still makes the decision." (Interviewee 5).

Dispute resolution processes are used to manage disputes between actors in the event of conflict regarding a decision. Collaborators expressed concerns regarding dispute resolution processes of both the Haida Gwaii Management Council and the Solutions Table; however, relatively greater confidence was expressed in the former.

In the absence of consensus among members of the Haida Gwaii 
Management Council, the neutral chairperson is expected to cast a deciding vote. Interviewees noted that by forcing the chairperson to take a position, this process has the potential to erode trust.

"I don't think it would be good for the relationship between the Haida and the Province for the Chair to have to come in and make a decision." (Interviewee 13).

At the Solutions Table, emergence of non-consensus issues led to the creation of a new process through which additional consultation is sought at a higher level of authority within both governments. The process was developed by collaborators and provides a transparent record of discussions that outlines areas of disagreement regarding issues that meet the technical requirements of the Land Use Objectives Order; however, these discussions are not required to result in consensus. This has generated concerns regarding influence and fairness.

"[...] the two senior level reps from each government [have] some dialogue to try to reach, or to try to bring it back to consensus. But it hasn't worked out to any solutions to date [...]" (Interviewee 12).

"[...] a proliferation of non-consensus means somebody needs to sort something out at a higher level." (Interviewee 7).

\subsection{Procedures and terms of reference}

Agreements were associated with procedures and terms of reference that provided specific guidance to actors. The Kunst'aa guu-Kunst'aayah Reconciliation Protocol, for example, includes the Streamlined Process, which outlines procedures for the Haida Gwaii Management Council and Solutions Table.

"Appendix A to the Streamlined Process [...] has 14 different Acts in it and it goes through all the different types of authorizations and whether they're Scenario $1 \mathrm{~s}$ or $2 \mathrm{~s}$. [It's] very key to how the process works." (Interviewee 4).

Procedures and terms of reference were described as important for establishing guidance for actors, including clarifying a shared vision, values and/or objectives and establishing accountability to those aspects. Developing procedures together was important for building trust, helped actors to clarify shared objectives and provided opportunities for actors to tackle challenges together. In situations where norms regarding relevant issues and knowledge differed among representatives of the two governments, terms of reference helped to bridge the divide by drawing attention back to a shared vision and objectives.

"We need to be in the room with a blank piece of paper and let's start together. [...] [W]hen we don't have that, there's just no trust." (Interviewee 1).

"The process of building the administrative structure [...] was pretty helpful, I think, in helping build that confidence [...] [I]t became a common effort." (Interviewee 15).

"[...] we do look at things differently and have different values but to date, because we have clear mandates, it's been pretty straightforward." (Interviewee 3).

Interviewees described that, while some procedures were formally established through documents such as the Streamlined Process, others were established collectively by actors themselves. The Haida Gwaii Management Council, for example, established a procedure to maintain continuity among members through staggered terms. This procedure was contrary to the Streamlined Process but helped knowledge and norms pass from one set of Council members to the next. Some interviewees noted challenges at the Solutions Table because the scope of responsibilities changed over time and new responsibilities were added without collaboratively developed institutional rules.

\subsection{Legislation}

Legislation and regulations, such as the Haida Gwaii Reconciliation Act (2010) and Land Use Objectives Order, were described by interviewees as both a result of distrust and a motivator for trust. Some interviewees pointed to the stringency and prescriptiveness of the Land Use Objectives Order as evidence of the lack of trust between the parties when the Kunst'aa guu-Kunst'aayah Reconciliation Protocol was negotiated. Others noted that these same characteristics helped to establish specific, shared objectives of the two parties, which served to motivate trust. These perspectives were complementary, rather than conflicting, and indicate the dual role of legislation and regulations. Interviewees from both governments and both collaborations expressed support for the Land Use Objectives Order and described it as a positive development. Joint development and implementation of the Haida Gwaii Reconciliation Act (2010) and the Land Use Objectives Order were noted as important characteristics for motivating trust.

"[The LUOO] gives you a recipe of what you have to do. The prescriptiveness of the objectives is what demonstrates a lack of [trust]." (Interviewee 7).

"We probably have the most stringent regulatory regime in the world on Haida Gwaii here. So, I feel good about that and I trust that we're managing that together very well." (Interviewee 1).

While several interviewees described the importance of representatives of the two parties working together to develop legislation and regulations, a few noted that these documents remain limited by the Provincial legislative framework. This creates a persistent imbalance in the level of influence each party can exert in the process, with the Council of the Haida Nation operating at a disadvantage.

\subsection{Norms}

Interviewees described norms related to honesty, permeability, respect, commitment and tackling challenges together. The first three relate to communication, while the latter two relate to behaviour. Honesty was noted to help actors to align interests through communication and required permeability to ensure actors were prepared to listen and be open to others' perspectives as well as respect for differences. Nested within the norm of honesty was an expectation of proactive information sharing, both among collaborators and with their respective organizations, that meant actors trusted others to raise any issues that were relevant to their collective role. Commitment and tackling challenges together enabled actors to persevere in times of disagreement and continue to seek consensus. A norm regarding commitment to seeking consensus was noted to both support decisionmaking and help avoid use of the dispute resolution process. Thus, the strength of this particular informal control enabled it to act as a substitute for formal controls.

Norms were noted to have been consciously shaped among actors during the early stages of collective action and continued thereafter; however, new actors experience a period of adjustment. A few interviewees from the Province of B.C. also noted the role of hiring and recruitment, through which actors are selected to participate in collective action, in maintaining these norms by selecting individuals who behave accordingly.

Shared values and beliefs were important for shaping norms; where differences existed, interviewees described struggling to act according to norms. Interviewees from both collaborations made statements that reflected values regarding which issues and what knowledge they felt were relevant during collective action. While interviewees from the Council of the Haida Nation tended to note the importance of traditional knowledge and a holistic approach to decisions that reflected the Haida value of Yahguudang (respect for all things), interviewees from the Province of B.C. referred more frequently to objective and science- 
based decisions that were seen to be within the mandate of the collaboration. In situations where actors disagreed about which topics were open to discussion or what information was admissible when making decisions, trust diminished. At times, distrust of one another's knowledge hindered actors' ability to shape collective norms related to relevant issues and knowledge. Norms of permeability and respect helped to mitigate the effects of differences in values;

"[...] there's Haida law and traditions and there's a whole slew of things [...] that aren't in Provincial mandate." (Interviewee 3).

Interviewees also noted differences between the two governments with respect to beliefs about influence. While the Haida governed forests on Haida Gwaii for millennia, the Province of B.C. has primarily assumed authority for decisions over the past 150 years. The Kunst'aa guu-Kunst'aayah Reconciliation Protocol recognizes these differences in beliefs "with regard to sovereignty, title, ownership and jurisdiction over Haida Gwaii" (Council of the Haida Nation and Province of British Columbia, 2009). Interviewees noted that these differences in beliefs have manifested in actors behaving according to norms regarding their organization's perceived level of influence, rather than a shared norm of equal influence established within the spirit of the Protocol. This was specifically noted with reference to handling of non-consensus issues among members of the Solutions Table by more senior level bureaucrats.

"[The Province has] done it a certain way for so long [...] I think it's kind of different for them." (Interviewee 3).

"I think that adds to a sense of lack of trust and the sense that we're not really true equals yet in this voyage that we're on." (Interviewee 13).

Norms were seen to have some degree of substitutability with procedures and terms of reference. For example, norms of honesty and proactive information sharing prompted actors to engage in practices that supported transparency in ways that were not formally documented in procedures and terms of reference.

\section{Discussion}

The case study and its underlying theoretical framework (Ostrom and Ahn, 2009) focused on how formal and informal institutions motivate trust; however, trust has also been shown to motivate development of institutions. For example, trust between individuals is important for establishing new collaborations (Coleman and Stern, 2018) and jointly developing institutions (Ansell and Gash, 2008; Emerson et al., 2012; Coleman and Stern, 2018). This finding supports the notion of a cyclical process through which designing institutions builds trust which can subsequently be reinforced by these institutions (Mayer et al., 1995; Nooteboom, 2005; Davis et al., 2018). The theoretical framework should thus recognize this cyclical relationship between institutions, trust and collective action.

Furthermore, while institutions may establish constraints that reduce the risk of defecting from collective action by reducing the benefits of defection and increase its costs, however, the role of individuals' personal characteristics and interpersonal relationships should not be overlooked. Micro-level influences on trust include psychological dimensions that are shaped by an individual's own life experiences and interactions with other actors (e.g. Mayer et al., 1995; Rousseau et al., 1998). While the case study focused on the characteristics of formal and informal rules that motivate trust, other areas of the literature that are relevant to the discussion are the characteristics of individuals and of interpersonal relationships. Ostrom and Ahn (2009) identify trustworthiness and networks as important for trust, but do not consider the role of individual characteristics. Integration of these aspects in further research can contribute to a more holistic theoretical framework for trust in the context of collective action.
The case study identified fourteen characteristics of formal and informal rules as having a positive influence on trust. These characteristics were reduced to four clusters: alignment of interests, fairness, cohesion and satisfactory terms of cooperation.

Alignment of interests, which is noted in the literature as having an influence on trust (Lewicki and Bunker, 1996; Bhattacharya et al., 1998; Das and Teng, 2001), encompassed elements of adaptability, shared beliefs, flexibility, responsiveness, shared values and shared vision. However, the case study also highlighted an important difference in shared values, with specific implications for norms of collective action: while the Haida value of Yahguudang asserts that everything is connected (Council of the Haida Nation, 2007), the Province of B.C. strictly adheres to jurisdictional authorities for decision-making (Pinkerton, 2007). This difference in approaches, which is described in the literature in terms of holism versus segmentalism (Pinkerton, 2007), created challenges among actors in this study who needed to determine what information and which issues were relevant to decision-making.

Fairness, which is noted in the literature (Newell and Swan, 2000; Dirks and Ferrin, 2002; Aryee et al., 2002), was linked to influence (Willem and Lucidarme, 2014) and unfettered authority. Equal influence, particularly in decision-making and joint dispute resolution processes, was particularly important. This finding is unsurprising given the potential for coercion (Williamson, 1993) in situations where power or influence are imbalanced. Joint development and implementation of the Haida Gwaii Reconciliation Act (2010) and the Land Use Objectives Order, as well as joint decision-making by the Haida Gwaii Management Council, were noted as examples where equal influence had motivated trust among actors. In contrast, provincial legislation that both established the decision-making authority of the statutory decision maker for the Province of B.C. and limited their discretion in decisionmaking made equal influence challenging for members of the Solutions Table, with negative consequences for trust.

Cohesion was expressed in terms of shared identity and stability. Shared identity is described in the trust literature with reference to identification: actors are more likely to trust others they identify as similar to themselves (Lewicki and Bunker, 1995, 1996; Bhattacharya et al., 1998) and be concerned for one another's outcomes (Bhattacharya et al., 1998). When fully developed, a shared identity can enable actors to internalize one another's desires and intentions (Lewicki and Bunker, 1995, 1996). Stability is noted in the literature with reference to continuity due to its role in generating expectations of behaviour among actors, supporting sequential actions and connecting the past with the present and future (North, 1991; Lewicki and Bunker, 1995; Bhattacharya et al., 1998; Poppo et al., 2008). From a game theory perspective, actors are more motivated to honour trust if interactions are repeated (Eberl, 2003).

Satisfactory terms of cooperation (Wong and Cheung, 2005), as perceived by collaborators, included aspects of accountability, development by collaborators, shared objectives and transparency (Willem and Lucidarme, 2014). These terms provided clarity and guidance to collaborators, supported alignment of interests and limited opportunism. Collaborators expressed greater satisfaction with terms that were developed jointly, rather than imposed by one party, suggesting a strong connection to fairness.

Indeed, the four clusters that emerged in this study demonstrated some degree of overlap. Shared objectives, for example, may be part of a broader shared vision. Satisfactory terms must reflect fairness and alignment of interests and cohesion may be supported by alignment of interests. Nevertheless, these clusters help to highlight overarching themes that unite the characteristics of rules that motivate trust.

These characteristics were described with reference to three forms of formal rules (agreements, procedures and terms of reference and legislation) and one form of informal rules (norms). While all four forms of rules were associated with alignment of interests, fairness and satisfactory terms of cooperation, only three forms of rules were associated with cohesion. The notable omission was legislation, which did 
not necessarily need to support cohesion to motivate trust. Instead, legislation functioned more as a tool to induce cooperation. Some researchers argue this is evidence of mere coordination or confidence, rather than of trust (Williamson, 1993; Eberl, 2003). The distinction is particularly murky because formal rules and trust can be either complements or substitutes (Woolthuis et al., 2005). Eberl (2003) emphasizes that trust includes an emotional dimension that "cannot be fully controlled by organizational measures." The case study showed that a sense of cohesion can be supported through procedures and terms of reference that document the shared nature of the relationship and support transitions between actors but that norms also play an important role. Elements of cohesion were both supported by norms, which contributed to a sense of shared identity and stability, and enabled the establishment of norms.

The case study also indicated some degree of substitutability between formal and informal rules. A norm regarding commitment to seeking consensus was noted to substitute for reliance on a dispute resolution process; however, existence of both controls safeguarded against breakdown in one or the other. Terms of reference also served as a substitute for norms among representatives of the two governments regarding what types of knowledge and issues are relevant to discussions. Evidence of the imperfect nature of this substitution is provided by non-consensus issues between the Council of the Haida Nation and the Province of B.C. at the Solutions Table. While the Kunst'aa guuKunst'aayah Reconciliation Protocol and the Streamlined Process formally outlined the relationship between the two parties, Haida norms of reliance on traditional knowledge and Yahguudang (respect for all things) continue to conflict with norms of Provincial representatives regarding objectivity, science-based decision-making and a focus on mandates.

While the case study focused on the role of formal and informal rules in motivating trust among actors, the social, economic and political setting in which these rules are created and operationalized also has profound effects (North, 1991; Williamson, 1993). In the framework presented by Ostrom and Ahn (2009), these contextual variables have important implications for trust. The Haida Gwaii Management Council and Solutions Table operate within federal and provincial legislative frameworks and, as such, are subject to established power dynamics that have created the potential for coercion and opportunism. The legacy of colonialism and history of assimilationist policy operationalized under this legislative framework continues to present a barrier to trust by and shifting the costs of defection from collective action onto the Council of the Haida Nation. In the event of non-consensus among members of the Solutions Table and a decision by the Provincial statutory decision-maker under their authority, established under the provincial legislative framework, the Council of the Haida Nation must bear the costs of a lawsuit or protest. While these terms were agreed to by both parties under the Kunst'aa guu-Kunst'aayah Reconciliation Protocol, the institutional environment has created forces that make power-sharing in collective action challenging.

The case study highlights fundamental differences in approaches to power and participation among the Council of the Haida Nation and the Province of B.C. The Kunst'aa guu-Kunst'aayah Reconciliation Protocol notes that "The Parties hold differing views with regard to sovereignty, title, ownership and jurisdiction over Haida Gwaii," with each claiming sovereignty (Council of the Haida Nation and Province of British Columbia, 2009). This would indicate an institutional collective action arrangement in which each party engages in collective action under its own authority, such as at the Haida Gwaii Management Council. The Solutions Table, however, operates akin to a collaborative governance arrangement in which the Council of the Haida Nation act in an advisory capacity as local resource users. This imbalance in the costs of defection was noted as a serious threat to trust.

\section{Conclusions}

This paper delved deeper into characteristics of institutions that motivate trust to support collective action. It focused on formal and informal rules and provided linkages to theoretical works from the trust literature and empirical case study of collaborative forest governance on Haida Gwaii. The case study identified fourteen characteristics of formal and informal rules that motivated trust. These characteristics were grouped into four clusters that highlight overarching themes among characteristics of rules that motivate trust: alignment of interests, fairness, cohesion and satisfactory terms of cooperation.

Jointly developing rules and ensuring they were adaptable to evolving needs over time was particularly important for motivating trust. Where distrust existed, such as during the early stages of collective action, some forms of formal rules acted as both a substitute for trust and a motivator for it. Informal rules, in the form of norms, were shaped by actors over the course of collective action. The case study also indicated some degree of substitutability between formal and informal rules; however, existence of both forms of rules safeguarded against breakdown in one or the other. Trust literature suggests that formal institutions may be relatively more important during early stages of collective action (Lewicki and Bunker, 1995; Bachmann and Inkpen, 2011). Over time, actors gain information about one another and relatively greater weight is placed on informal rules and interpersonal relationships (Lewicki and Bunker, 1995; Bachmann and Inkpen, 2011). Longitudinal or comparative case study approaches that examine relative influences of formal and informal rules over time are needed to test these theories.

The case study also highlights the importance of power-sharing for trust. While the trust literature identifies characteristics of institutions that motivate trust, some of which relate to power-sharing, contextual variables can limit the degree to which power is shared and constrain the potential to create trust. This may be particularly relevant to cases of collective action involving Indigenous and non-Indigenous governments, where parties disagree on their respective authorities.

An important next step in this area of research would be to develop studies to better understand the influence of institutional characteristics on trust and to identify measureable outcomes of collective action. Exploring situations where participants make decisions under different sets of rules can help to predict actions and outcomes in a range of institutional settings. This type of information could be used to develop rules that support collective action among actors who manage commonpool resources.

\section{Acknowledgments}

The authors wish to express their gratitude to the Council of the Haida Nation for its interest and participation in this research and to the seventeen interviewees who made time to share their experiences. Two discussants and two co-editors of this special issue also provided invaluable feedback that improved the quality of this manuscript. This work was supported by the Social Sciences and Humanities Research Council (SSHRC) of Canada.

\section{References}

Aligica, P.D., Boettke, P., 2009. Challenging Institutional Analysis and Development: the Bloomington School. Routledge, New York.

Aligica, P.D., Boettke, P., 2011. The two social philosophies of Ostroms' institutionalism. Policy Stud. J. 39 (1), 23-43.

Ansell, C., Gash, A., 2008. Collaborative governance in theory and practice. J. Public Adm. Res. Theory 18 (4), 543-571.

Armitage, D., Berkes, F., Doubleday, N. (Eds.), 2007. Adaptive co-Management: collaboration, Learning, and MultiLevel Governance. University of British Columbia Press, 
Vancouver, BC

Aryee, S., Budhwar, P.S., Chen, Z.X., 2002. Trust as a mediator of the relationship between organizational justice and work outcomes: test of a social exchange model. J. Organ. Behav. 23, 267-285.

Bachmann, R., Inkpen, A.C., 2011. Understanding institutional-based trust building processes in inter-organizational relationships. Organ. Stud. 32 (2), 281-301.

BC MFLNRO, September 20, 2012. British Columbia Ministry of Forests, Lands and Natural Resource Operations. In: Rationale for Allowable Annual Cut (AAC) Determinations for Tree Farm Licence 58, Tree Farm Licence 60, and Timber Supply Area 25, . https://www2.gov.bc.ca/assets/gov/farming-natural-resources-andindustry/forestry/stewardship/forest-analysis-inventory/tsr-annual-allowable-cut/ queen_charlotte_tsa_rationale.pdf, Accessed date: 11 octubre 2018.

Berkes, F., 2009. Evolution of co-management: role of knowledge generation, bridging organizations and social learning. J. Environ. Manag. 90, 1692-1702.

Berkes, F., 2010. Devolution of environment and resources governance: trends and future. Environ. Conserv. 37 (4), 489-500.

Bhattacharya, R., Devinney, T.M., Pillutla, M.M., 1998. A formal model of trust based on outcomes. Acad. Manag. Rev. 23 (2), 459-472.

Blackstock, M.D., 2001. Where is the trust? Using trust-based mediation for first nations dispute resolution. Conflict Resolut. Q. 19 (1), 9-30.

Bowie, R., 2013. Indigenous self-governance and the deployment of knowledge in collaborative environmental management in Canada. J. Can. Stud. 47 (1), 91-121.

Canada, Erasmus, G., Dussault, R., 1996. Report of the Royal Commission on Aboriginal Peoples. The Commission, Ottawa.

Carlson, K., 2010. The Power of Place, the Problem of Time: aboriginal Identity and Historical Consciousness in the Cauldron of Colonialism. University of Toronto Press, Toronto, ON.

Castaldo, S., 2002. Meanings of trust: a meta-analysis of trust definitions. In: Paper Presented at the Annual Conference of Euram, Stockholm, Sweden, May, pp. 9-11.

Castelfranchi, C., Falcone, R., 2010. Trust Theory: a Socio-Cognitive and Computational Model. Wiley \& Sons, New York.

Coates, K., Carlson, K.T., 2013. Different peoples, Shared Lands: historical perspectives on native-newcomer relations surrounding resource use in British Columbia. In: Tindall (Ed.), Aboriginal Peoples and Forest Lands in Canada. UBC Press, Vancouver, BC, pp. $15-30$.

Coleman, J.S., 1990. Foundations of Social Theory. Harvard University Press, Cambridge, MA.

Coleman, K., Stern, M.J., 2018. Exploring the functions of different forms of trust in collaborative natural resource management. Soc. Nat. Resour. 31 (1), 21-38.

Coletti, A.L., Sedatole, K.L., Towry, K.L., 2005. The effect of control systems on trust and cooperation in collaborative environments. Account. Rev. 80 (2), 477-500.

Colquitt, J.A., Scott, B.A., LePine, J.A., 2007. Trust, trustworthiness, and trust propensity: a meta-analytic test of their unique relationships with risk taking and job performance. J. Appl. Psychol. 92 (4), 909-927.

Council of the Haida Nation, 2007. Towards a Marine use Plan for Haida Gwaii: a Discussion Paper. https://www.ceaa-acee.gc.ca/050/documents_staticpost/cearref 21799/83896/Discussion_Paper_-_Towards_a_Marine_Use_Plan.pdf, Accessed date: 26 octubre 2018.

Council of the Haida Nation, November 2010. Athlii Gwaii - 25 years down the road. In: Haida Laas - Journal of the Haida Nation, . http://www.haidanation.ca/wp-content/ uploads/2017/03/jl_nov.10.pdf, Accessed date: 26 octubre 2018.

Council of the Haida Nation and Province of British Columbia, 2007. Haida Gwaii Strategic Land Use Agreement. https://www.for.gov.bc.ca/tasb/slrp/docs/Haida SLUPA_Dec 07.pdf, Accessed date: 26 octubre 2017.

Council of the Haida Nation and Province of British Columbia, 2009. Kunst'aa Guu Kunst'aayah Reconciliation Protocol. https://coastalfirstnations.ca/wp-content/ uploads/2017/06/haida_rp_fully_signed_and_dated_-jan_22_2016-1.pdf, Accessed date: 26 octubre 2018.

Council of the Haida Nation and the Province of British Columbia, 2017. Haida Gwaii Land Use Objectives Order (Consolidated Version). https://www2.gov.bc.ca/assets/ gov/farming-natural-resources-and-industry/natural-resource-use/land-water-use/ crown-land/land-use-plans-and-objectives/westcoast-region/haidagwaii-slua/ haidagwaii_slua_luor_8may2014consolidated.pdf, Accessed date: 26 octubre 2018.

Crawford, S.E.S., Ostrom, E., 2005. A grammar of institutions. In: Ostrom, E. (Ed.), Understanding Institutional Diversity. Princeton University Press, Princeton, NJ, pp. 137-174.

Das, T.K., Teng, B.-S., 2001. Trust, control, and risk in strategic alliances: an integrated framework. Organ. Stud. 22, 251-283.

Das, T.K., Teng, B.-S., 2004. The risk-based view of trust: a conceptual framework. J. Bus. Psychol. 19 (1), 85-116

Davey, J.W., Gugiu, P.C., Coryn, C.L.S., 2010. Quantitative methods for estimating the reliability of qualitative data. J. MultiDiscip. Eval. 6 (13), 140-162.

Davis, D.D., Holt, C.A., 1993. Experimental Economics. Princeton University Press, Princeton, NJ.

Davis, E.J., Cerveny, L.K., Ulrich, D.R., Nuss, M.L., 2018. Making and breaking trust in forest collaborative groups. Humboldt J. Soc. Relat. 1 (40), 211-231.

Dean, M., 2009. "What they are doing to the land, they are doing to us": environmental politics on Haida Gwaii. In: A thesis submitted in partial fulfillment of the requirements for the degree of Master of Arts in the Faculty of Graduate Studies (History). The University of British Columbia, Vancouver.

Dirks, K.T., Ferrin, D., 2002. Trust in leadership: meta-analytic findings and implications for research and practice. J. Appl. Psychol. 87, 611-628.

Dowie, M., 2017. The Haida Gwaii Lesson: a Strategic Playbook for Indigenous Sovereignty. Inkshares, Oakland, CA

Eberl, P., 2003. The development of trust and implications for organizational design: a game- and attribution-theoretical framework. Schmalenbach Bus. Rev. 56, 258-273.
Egan, B., 2011. Resolving 'the Indian Land Question'? Racial rule and Reconciliation in British Columbia. In: Baldwin, A., Cameron, L., Kobayashi, A. (Eds.), Rethinking the Great White North: race, Nature and Historical Geographies of Whiteness in Canada. UBC Press, Vancouver and Toronto, pp. 211-232.

Emerson, K., Nabatchi, T., Balogh, S., 2012. An integrative framework for collaborative governance. J. Public Adm. Res. Theory 22, 1-29.

Environment Canada, 1980. Canadian climate normals, 1951-1980. In: Temperature and Precipitation, British Columbia. Atmospheric Environment Service, Downsview, Ontario, pp. 268

Farrell, H., 2009a. Trust, distrust and power. In: Hardin, R. (Ed.), Distrust. Russell Sage Foundation, New York, NY, pp. 85-105.

Farrell, H., 2009b. Chapter 5: institutions and mid-level explanations of trust. In: Cook, K.S., Levi, M., Hardin, R. (Eds.), Whom Can We Trust?: how Groups, Networks, and Institutions Make Trust Possible. Russell Sage Foundation, New York, NY.

Feiock, R., 2013. The institutional collective action framework. Policy Stud. J. 41 (3), $397-425$.

Feiock, R., Scholz, J.T., 2010. Self-Organizing Federalism: collaborative Mechanisms to Mitigate Institutional Collective Action Dilemmas. Cambridge University Press, New York, NY.

Lessons from the Islands: introduced species and what they tell us about how ecosystems work. Proceedings from the Research Group on Introduced Species 2002 Symposium. In: Gaston, A.J., Golumbia, T.E., Martin, J.-L., Sharpe, S.T. (Eds.), Queen Charlotte City, Queen Charlotte Islands, British Columbia. Canadian Wildlife Service, Environment Canada, Ottawa.

George, D., Mallery, P., 2003. SPSS for Windows Step by Step: a Simple Guide and Reference, 11.0 Update, 4th ed. Allyn \& Bacon, Boston, MA.

Gillespie, N., 2003. Measuring trust in work relationships: the Behavioural Trust Inventory. In: paper presented at the Academy of Management Conference, Seattle

Gillespie, N., 2012. Measuring trust in organizational contexts: an overview of surveybased measures. In: Lyon, F., Möllering, G., Saunders, M.N.K. (Eds.), Handbook of Research Methods on Trust. Edward Elgar, Northampton, MA.

Haida Nation v. British Columbia, 2004. (Minister of Forests), 3 S.C.R. 511. pp. 73 SCC.

Hardin, G., 1968. The Tragedy of the Commons. Science 162 (3859), 1243-1248.

Hotte, N., Wyatt, S., Kozak, R., 2019. Influences on trust during collaborative forest governance: a case study from Haida Gwaii. Can. J. For. Res. 361-374.

Janssen, M.A., Ostrom, E., 2006. Empirically based, agent-based models. Ecol. Soc. 11 (2), 37.

Jones, R., Rigg, C., Pinkerton, E., 2017. Strategies for assertion of conservation and local management rights: a Haida Gwaii herring story. Mar. Policy 80, 154-167.

Kahan, D., 2003. The logic of reciprocity: trust, collective action, and law. Michigan Law Rev. 102 (1), 71-103.

Keefer, P., Knack, S., 2005. Social capital, social norms and the new institutional economics. In: Menard, C., Shirley, M.M. (Eds.), Handbook of New Institutional Economics. Springer, New York, NY.

Kiser, L.L., Ostrom, E., 1982. The three worlds of action: a Metatheoretical synthesis of institutional approaches. In: Ostrom, E. (Ed.), Strategies of Political Inquiry. Sage, Beverly Hills, CA.

Kramer, R.M., Tyler, T.R. (Eds.), 1996. Trust in Organizations: frontiers of Theory and Research. Sage, New York, NY.

Lee L., 2012. People, Land and Sea: Environmental Governance on Haida Gwaii. 19 pp.

Haida Gwaii Reconciliation Act, S.B.C. 2010, c. 17 (Bill 18), Queen's Printer

Lewicki R.J. and Bunker, B., 1995. Trust in relationships: A model of development and decline. In: Bunker B.B. and Rubin J.Z. (Ed.), The Jossey-Bass management series and The Jossey-Bass conflict resolution series. Conflict, cooperation, and justice: Essays inspired by the work of Morton Deutsch. Jossey-Bass, San Francisco, CA, US, pp 133-173.

Lewicki R.J. and Bunker, B., 1996. Developing and maintaining trust in work relationships. In: Kramer R.M. and Tyler T.R (Ed.), Trust in Organizations: Frontiers of Theory and Research. Sage Publications, Thousand Oaks, CA, USA, pp. 114-139 $440 \mathrm{pp}$.

Marshall, G., 1998. A Dictionary of Sociology. Oxford University Press, New York.

Mayer, R.C., Davis, J.H., Schoorman, F.D., 1995. An integrative model of organizational trust. Acad. Manag. Rev. 20 (3), 709-734.

McKnight, D.H., Cummings, L.L., Chervany, N.L., 1998. Initial trust formation in new organizational relationships. Acad. Manag. Rev. 23 (3), 473-490.

Möllering, G., 2006. Trust, institutions, agency: towards a neoinstitutional theory of trust. In: Bachmann, R., Zaheer, A. (Eds.), Handbook of Trust Research. Edward Elgar, Northampton, MA, pp. 355-376.

National Centre for First Nations Governance, 2013. The Governance Toolkit. http:// bcafn.ca/wp-content/uploads/2016/06/Governance-Toolkit.pdf, Accessed date: 26 octubre 2018.

Newell, S., Swan, J., 2000. Trust and inter-organizational networking. Hum. Relat. 53 (10), 1287-1328.

Nooteboom, B., 2005. Trust, Institutions and Development. Tilburg University, Netherlands.

North, D., 1990. Institutions, Institutional Change and Economic Performance. Cambridge University Press, Cambridge, UK.

North, D., 1991. Institutions. J. Econ. Perspect. 5 (1), 97-112.

Olson, M., 1965. The Logic of Collective Action: public Goods and the Theory of Groups. Harvard University Press, Cambridge, MA.

Ostrom, V., 1980. Artisanship and Artifact. Public Adm. Rev. 40, 309-317.

Ostrom, E., 1986. An agenda for the study of institutions. Public Choice 48 (1), 3-25.

Ostrom, E., 1990. Governing the Commons: the Evolution of Institutions for Collective Actions. Cambridge University Press, Cambridge, UK.

Ostrom, E., 2003. Toward a behavioral theory linking trust, reciprocity, and reputation. In: Ostrom, E., Walker, J. (Eds.), Trust and Reciprocity: interdisciplinary Lessons from 
Experimental Research. Russell Sage Foundation, New York, NY, pp. 19-79. Ostrom, E., 2005. Understanding Institutional Diversity. Princeton University Press, Princeton, NJ.

Ostrom, E., 2009. Beyond markets and states: polycentric governance of complex economic systems. In: The Sveriges Riksbank Prize in Economic Sciences in Memory of Alfred Nobel 2009. Prize Lecture, December 8. https://www.nobelprize.org/ uploads/2018/06/ostrom_lecture.pdf, Accessed date: 26 octubre 2018.

Ostrom, E., 2011. Background on the institutional analysis and development framework. Policy Stud. J. 39 (1), 7-27.

Ostrom, E., Ahn, T.K., 2009. Chapter 2: the meaning of social capital and its link to collective action. In: Svendsen, G.T., Svendsen, G.L.H. (Eds.), Handbook of Social Capital. Edward Elgar, Cheltenham, UK, pp. 17-35.

Ostrom, E., Walker, J. (Eds.), 2003. Trust and Reciprocity: Iinterdisciplinary lessons from Experimental Research. Russell Sage Foundation, New York, NY.

Papillon, M., 2015. Introduction: the promises and pitfalls of Aboriginal multilevel governance. In: Papillon, M., Juneau, A. (Eds.), Canada: the State of the Federation, 2013: aboriginal Multilevel Governance. McGill-Queen's University Press, Kingston, ON, pp. 3-26.

Penikett, T., September 2012. Six definitions of aboriginal self-government and the unique Haida model. In: Prepared for the Action Canada Northern Conference, Haida Gwaii, . http://www.actioncanada.ca/wp-content/uploads/2014/04/Haida-GwaiiGovernance-EN-Oct-2012.pdf, Accessed date: 26 octubre 2018.

Pinkerton, E. (Ed.), 1989. Co-Operative Management of Local Fisheries. University of British Columbia Press, Vancouver, BC

Pinkerton, E., 2007. Integrating holism and segmentalism: overcoming barriers to adaptive co-management between management agencies and multi-sector bodies. In: Armitage, D., Berkes, F., Doubleday, N. (Eds.), Adaptive Co-Management: collaboration, Learning and Multi-Level Governance. UBC Press, Vancouver, BC, pp. 151-171.

Poppo, L., Zhou, K.Z., Ruy, S., 2008. Alternative origins to Interorganizational trust: an interdependence perspective on the shadow of the past and the shadow of the future. Organ. Sci. 19 (1), 39-55.

Poteete, A., Janssen, M., Ostrom, E., 2009. Multiple Methods in Practice: collective Action and the Commons. Princeton University Press, Trenton, NJ.

Prabhu, R., McDougall, C., Fisher, R., 2007. Adaptive collaborative management: a conceptual model. In: Fisher, R., Brabhu, R., McDougall, C. (Eds.), Adaptive Collaborative Management of Community Forests in Asia. Center for International Forestry Research, Bogor, Indonesia, pp. 16-49.

Pretty, J., Ward, H., 2001. Social capital and the environment. World Dev. 29 (2), 209-227.

Rapoport, A., Chammah, A.M., 1965. Prisoner's Dilemma: a Study in Conflict and
Cooperation. University of Michigan Press, Ann Arbor, Michigan.

Ribot, J., Agrawal, A., Larson, A., 2006. Recentralizing while decentralizing: how national governments reappropriate forest resources. World Develop. 34, 1864-1886.

Rousseau, D.M., Sitkin, S.B., Burt, R.S., Camerer, C., 1998. Not so different after all: a cross-discipline view of trust. Acad. Manag. Rev. 23, 393-404.

Rubin, H.J., Rubin, I.S., 2005. Qualitative Interviewing - The Art of Hearing Data, 2nd edition. Sage, New York, NY.

Ryan, G.W., Bernard, H.R., 2003. Techniques to identify themes. Field Methods 15 (1), 85-109.

Schaubroeck, J., Lam, S.S.K., Peng, A.C., 2011. Cognition-based and affect-based trust as mediators of leader behavior influences on team performance. J. Appl. Psychol. 96, 863-871.

Schilke, O., Reimann, M., Cook, K.S., 2015. Power decreases trust in social exchange. PNAS 112 (42)

Schoorman, F.D., Mayer, R.C., Davis, J.H., 2007. An integrative model of organizational trust. Acad. Manag. Rev. 32 (2), 344-354.

Seppanen, R., Blomqvist, K., Sundqvist, S., 2007. Measuring inter-organizational trust: a critical review of the empirical research in 1990-2003. Ind. Mark. Manag. 36 (2), 249-265.

Shapiro, D.B., Sheppard, H., Cheraskin, L., 1992. Business on a handshake. Negotiation J. 8 (4), 365-377

Sheppard, B.H., Sherman, D.M., 1998. The grammars of trust: a model and general implications. Acad. Manag. Rev. 23 (3), 422-437.

Singleton, S., 1998. Constructing Cooperation: the Evolution of Institutions of Comanagement. University of Michigan Press, Ann Arbor, Michigan.

Takeda, L., Røpke, I., 2010. Power and contestation in collaborative ecosystem-based management: the case of Haida Gwaii. Ecol. Econ. 70 (2), 178-188.

Vanni, F., 2014. Agriculture and public goods: the role of collective action. In: Springer Netherlands. Dordrecht, Netherlands.

Willem, A., Lucidarme, S., 2014. Pitfalls and challenges for trust and effectiveness in collaborative networks. Public Manag. Rev. 16 (5), 733-760.

Williamson, O., 1993. Calculativeness, trust and economic organization. J. Law Econ. 36, $453-486$.

Wong, P.S.P., Cheung, S.O., 2005. Structural equation model of trust and partnering success. J. Manag. Eng. 21 (2), 70-80.

Woolthuis, R.K., Hillebrand, B., Nooteboom, B., 2005. Trust, contract and relationship development. Organ. Stud. 26, 813-840.

Wu, C., Wilkes, R., 2016. Durable power and generalized trust in everyday social exchange. Proc. Natl. Acad. Sci. 113 (11), E1417.

Yamagishi, T., Yamagishi, M., 1994. Trust and commitment in the United States and Japan. Motiv. Emot. 129-166. 